\title{
The Autolysis of Aspergillus terreus in a Physiologically Acid Medium
}

\author{
By R. LAHOZ, F. REYES, R. BELTRÁ AND C. GARCÍ A-TAPIA \\ Instituto 'Jaime Ferrán' de Microbiologia, del Consejo Superior de \\ Investigaciones Cientificas, Joaquin Costa 32, Madrid-6, Spain
}

(Accepted for publication 9 May 1967)

\begin{abstract}
SUMMARY
The behaviour of certain intracellular components contained in the mycelium of Aspergillus terreus during autolysis were studied. Aspergillus terreus grown in an acid medium underwent an 'acid autolysis' in which a decrease in mycelial dry weight amounting to $14.6 \%$ occurred. The content of fat present in the autolysing mycelium continuously decreased throughout the pre-autolytic and autolytic stages. The concentration of free glucose in the mycelium continuously increased at the beginning of autolysis, whereas xylose soon disappeared when autolysis began. At the end of the log phase and during the pre-autolytic stages the content of mannitol sharply decreased, at the beginning of autolysis its concentration decreased at a slower rate, being constant at the end of the autolytic period studied. Fourteen different amino acids were found in the autolysing mycelium of $A$. terreus. Eighty-six $\%$ of the maximum concentration of these free amino acids disappeared from mycelium before autolysis; $81 \%$ of the remainder during autolysis.
\end{abstract}

\section{INTRODUCTION}

Studies on the chemistry of the autolytic phase of growth in filamentous fungi grown in physiologically alkaline and acid media have been reported only on three occasions for four different moulds: Aspergillus niger (Behr, 1930); Cunninghamella elegans (Schmidt, 1936); Mucor adventitius and Absidia glauca (Ritter, 1955). In these studies the behaviour of certain nitrogenous compounds during autolysis, in two types of medium $\left(\mathrm{NO}_{3}^{-}\right.$or $\mathrm{NH}_{4}^{+}$as $\mathrm{N}$ source) were described. However, very few papers have presented quantitative data on the variation of the amount of intracellular free sugars and free amino acids contained in autolysing mycelium in cultures on an acid medium.

Continuing our work on the chemistry of autolysis in fungi we reported in a previous paper (Lahoz, I967) the behaviour of Aspergillus terreus grown in an alkaline medium, during autolysis. The present work describes the qualitative and quantitative chemical changes in lipids, free sugars, mannitol and free amino acids occurring in $A$. terreus grown in an acid medium during the autolytic phase of growth.

\section{METHODS}

Organism. Aspergillus terreus Thom (our collection no. 2426) was used as a physiological model in the present studies with a liquid medium.

Chemicals. Chemicals used in the preparation of the culture medium were of 
analytical purity, all obtained from Probus, S. A. (Barcelona, Spain). Other chemicals used were either from the British Drug Houses Ltd. (Poole, Dorset, England) or from Sigma Chemical Co. (St Louis, Mo., U.S.A.).

Culture medium and cultivation of the organism. The organism was grown in static cultures in a modified Czapek-Dox medium, in which the source of nitrogen, $\mathrm{NaNO}_{3}$, was replaced by its equivalent amount of $\left(\mathrm{NH}_{4}\right)_{2} \mathrm{SO}_{4}$, thus leading to an 'acid autolysis'. The medium had the following composition: glucose (anhydrous) $50 \mathrm{~g}$.; $\left(\mathrm{NH}_{4}\right)_{2} \mathrm{SO}_{4} \mathrm{I} \cdot 55 \mathrm{~g}$.; $\mathrm{KCl} 0.5$ g.; $\mathrm{MgSO}_{4} \cdot 7 \mathrm{H}_{2} \mathrm{O} 0.5$ g.; $\mathrm{KH}_{2} \mathrm{PO}_{4} \mathrm{I} \cdot 0$ g.; $\mathrm{FeSO}_{4} \cdot 7 \mathrm{H}_{2} \mathrm{O}$ $0.0 \mathrm{I} \mathrm{g.;} \mathrm{distilled} \mathrm{water} \mathrm{rooo} \mathrm{ml}$. Fifteen 1 . of this medium were prepared and distributed in $100 \mathrm{ml}$. portions in Jena glass conical flasks of $300 \mathrm{ml}$. capacity. The flasks were plugged with non-absorbant cotton wool and sterilized by steaming on three consecutive days, for $30 \mathrm{~min}$. each day. When at room temperature, a heavy spore suspension of Aspergillus terreus was inoculated (about $2 \mathrm{ml}$.) into each flask. These flasks were then incubated at $24-25^{\circ}$ in the dark.

Samples ( 5 flasks) were withdrawn at intervals from the incubator. The mycelia were separated from the culture fluids by filtration. These culture fluids from 5 flasks were pooled and diluted with distilled water to the original volume. The mycelia were washed free from culture fluid with distilled water, cut into small pieces and dried to constant weight at $60-70^{\circ}$.

Fractionation of mycelium. Weighed samples of powdered mycelium harvested at different times were exhaustively extracted with light petroleum (b.p. 50-70 ). The solvent was removed from the extract by distillation and the crude lipids left in the flask dried in vacuum to constant weight; this constituted fraction I. The defatted mycelium was carefully removed from the percolator, dried at $80^{\circ}$, weighed and extracted twice by cold $\left(22^{\circ}\right)$ distilled water ( $100 \mathrm{ml} . / \mathrm{g}$. dry defatted mycelium) with mechanical stirring for I hr. The cold-water extracts were combined and stored at $-10^{\circ}$ until needed (fraction 2). To test for completeness of extraction the residue was a third time extracted and the resulting extract concentrated under reduced pressure and a sample of it chromatographed to examine for sugars and amino acids.

One hundred $\mathrm{ml}$. of fraction 2 were concentrated in vacuum at $70^{\circ}$ on a water bath to a final volume of $10 \mathrm{ml}$. Portions $(0.5$ or $0.7 \mathrm{ml}$.) of this concentrate were used for chromatographic analysis of sugars and mannitol. The remainder of each concentrate was kept at $-10^{\circ}$.

The determination of total nitrogen, fat, total free reducing substances, free sugars and mannitol were as described previously (Lahoz, Reyes \& Beltrá, I966).

Estimation of individual amino acids. One hundred $\mathrm{ml}$. of fraction 2 were concentrated to dryness at $60-70^{\circ}$ under reduced pressure and extracted with $50 \mathrm{ml}$. of the ethanol + water + conc. $\mathrm{HCl}(95+4.5+0.5$, by vol. $)$ mixture described by Baliga, Krishnamurthy, Rajagopalan \& Giri (1955). This extract was concentrated and the amino acids separated and identified by paper chromatography using as solvent the butan-l-ol + acetic acid $+96 \%(\mathrm{v} / \mathrm{v})$ ethanol + water $(40+10+10+20$, by vol. $)$ mixture on Whatman no. I filter paper. The papers were developed by descending chromatography in three successive periods of $24 \mathrm{hr}$ runs, each time air-dried and newly introduced into the tank for a total time of $72 \mathrm{hr}$. Elution of the spots and determination of the amount of each of the individual amino acids was done by the method of Giri, Radhakrishnan \& Vaidyanathan (I953) as modified by Kay, Harris \& Entenman (I956). Readings were done in a Beckman spectrophotometer, model B at $575 \mathrm{~m} \mu$. Standards were 
prepared from leucine of analytical purity obtained from Sigma Chemical Co. (St Louis, Mo., U.S.A.). Results are expressed as g. amino acid/100 g. dry mycelium.

Total phosphorus. This was determined by a modification of the method of Fiske \& SubbaRow (1925).

\section{RESULTS}

Autolysis of Aspergillus terreus in a medium containing $\mathrm{NH}_{4}^{+}$as $\mathrm{N}$ source took place at about pH 2 (Table $\mathrm{r}$ ). Dry weight of mycelium (Table 2 ) reached a maximum, $1 \cdot 0824 \mathrm{~g}$./flask, at the I 8 th day of incubation and was $0.9242 \mathrm{~g}$./flask at the 150 th day

Table I. The autolysis of Aspergillus terreus in cultures in an acid ( $\mathrm{pH} 2)$ medium at $24-25^{\circ}$ in the dark. $p H$ values residual glucose, nitrogen and phosphorus of the culture fluid at various times of incubation

\begin{tabular}{|c|c|c|c|c|c|}
\hline $\begin{array}{l}\text { Time of } \\
\text { incubation } \\
\text { (days) }\end{array}$ & $\begin{array}{l}\text { Time of } \\
\text { autolysis } \\
\text { (days) }\end{array}$ & $\mathrm{pH}$ value & $\begin{array}{c}\text { Residual } \\
\text { glucose } \\
\text { (g./ / } 00 \mathrm{ml} .)\end{array}$ & $\begin{array}{c}\text { Nitrogen } \\
\text { (mg./100 ml.) }\end{array}$ & $\begin{array}{l}\text { Phosphorus } \\
\text { (mg./100 ml.) }\end{array}$ \\
\hline 6 & . & $1 \cdot 8$ & $2 \cdot 950$ & 0.00 & 15.5 \\
\hline 7 & . & $I \cdot 9$ & $2 \cdot 700$ & 0.00 & 15.5 \\
\hline 8 & . & $1 \cdot 8$ & $1 \cdot 440$ & 0.00 & 147 \\
\hline 9 & . & $1 \cdot 8$ & $1 \cdot 360$ & 0.00 & 14.9 \\
\hline 10 & . & I. 9 & 0.790 & 0.00 & $13 \cdot 8$ \\
\hline 11 & . & $2 \cdot 0$ & 0.590 & 0.00 & 13.5 \\
\hline I 2 & . & I.9 & 0.310 & 0.00 & $14 \cdot 8$ \\
\hline 13 & . & 1.9 & 0.300 & 0.00 & I 5.8 \\
\hline 14 & . & $2 \cdot 0$ & 0.200 & 0.00 & 17.5 \\
\hline I 5 & . & $2 \cdot I$ & 0.140 & 0.00 & I 8.8 \\
\hline 18 & o & $2 \cdot 1$ & 0.053 & 0.00 & $20 \cdot 5$ \\
\hline 24 & 6 & $2 \cdot 0$ & 0.060 & $5 \cdot 10$ & $21 \cdot 3$ \\
\hline 30 & 12 & $2 \cdot 1$ & 0.054 & $8 \cdot 10$ & . \\
\hline 42 & 24 & $2 \cdot I$ & . & $8 \cdot 76$ & . \\
\hline 54 & 36 & . & . & $8 \cdot 63$ & . \\
\hline 66 & 48 & $2 \cdot 0$ & . & 8.00 & . \\
\hline 78 & 60 & . & . & $6.9 I$ & . \\
\hline 90 & 72 & . & . & $10 \cdot 70$ & . \\
\hline 102 & 84 & . & . & 9.00 & . \\
\hline II 4 & 96 & . & . & 8.90 & . \\
\hline I 26 & 108 & . & . & $9 \cdot 50$ & . \\
\hline 138 & 120 & $1 \cdot 9$ & . & $9 \cdot 20$ & . \\
\hline 150 & I 32 & . & . & $8 \cdot 89$ & . \\
\hline 162 & 150 & . & . & 6.80 & . \\
\hline
\end{tabular}

of autolysis. The loss in mycelial dry weight amounted to $14.6 \%$ during this autolytic period. The criterion of autolysis we have adopted throughout this work was the loss in mycelial weight. According to that, autolysis began on the I9th day of incubation. Carbon source (glucose) initially present at $5 \mathrm{~g}$./ $100 \mathrm{ml}$. medium, reached an average constant value $0.055 \mathrm{~g}$./ $100 \mathrm{ml}$. culture filtrate (Table I), after the zero day of autolysis. A progressive increase in the content of total $\mathrm{P}$ in the culture filtrate during the pre-autolytic stages occurred (Table I). Nitrogen was not detected in the culture filtrate between the 6th and the I8th days of incubation; at the $24^{\text {th }}$ day $5^{\circ} \mathrm{mg}$. $\mathrm{N} / \mathrm{roO} \mathrm{ml}$. were present.

The percentage of nitrogen in autolysing mycelium of Aspergillus terreus (Table 2) grown with $\left(\mathrm{NH}_{4}\right)_{2} \mathrm{SO}_{4}$ as $\mathrm{N}$ source decreased slowly through the whole period of incubation, reaching a minimum constant value, $2 \cdot 1 \%$, at the 96 th day of autolysis. The amount of total $\mathrm{P}$ present in mycelium during the incubation period here studied 
decreased by about a half $(54 \%)$ with respect to its initial maximum content, whereas the disappearance of $\mathbf{P}$ during the first 24 days of autolysis amounted to $75 \%$ (Table 2 ). The highest amount of fat present in mycelium of $A$. terreus was observed at the 9 th day of incubation. From this stage on the content of fat continuously decreased during the whole cycle of autolysis, being $4.9 \mathrm{~g}$./100 g. dry mycelium (Table 2), the final value observed at the end of the autolytic period (I50 days).

Table 2. The autolysis of Aspergillus terreus in cultures in an acid medium at $24-25^{\circ}$ in the dark

\begin{tabular}{|c|c|c|c|c|c|}
\hline $\begin{array}{l}\text { Time of } \\
\text { incubation } \\
\text { (days) }\end{array}$ & $\begin{array}{l}\text { Time of } \\
\text { autolysis } \\
\text { (days) }\end{array}$ & $\begin{array}{c}\text { Mycelium } \\
\text { dry weight } \\
\text { (g./flask) }\end{array}$ & $\begin{array}{c}N \\
(\%)\end{array}$ & $\begin{array}{l}\mathrm{P} \\
(\%)\end{array}$ & $\begin{array}{c}\text { Fat } \\
\text { (g./100 g. } \\
\text { dry mycelium) }\end{array}$ \\
\hline 6 & . & 0.6695 & $4 \cdot 7$ & . & . \\
\hline 7 & . & 0.7988 & $3 \cdot 4$ & 0.96 & 19.0 \\
\hline 8 & . & 0.8907 & . & 0.96 & . \\
\hline 9 & . & 0.9264 & $2 \cdot 8$ & 0.92 & $2 \mathrm{I} \cdot 6$ \\
\hline 10 & . & 0.9540 & . & 0.94 & . \\
\hline I I & . & I.0090 & . & 0.87 & $20 \cdot 5$ \\
\hline 12 & . & I.0380 & . & 0.74 & . \\
\hline 13 & . & $1 \cdot 0652$ & . & 0.68 & . \\
\hline 14 & . & I.0589 & $2 \cdot 6$ & 0.53 & . \\
\hline I 5 & . & $1 \cdot 0770$ & . & . & $15 \cdot 8$ \\
\hline I 8 & 0 & I.0824 & . & 0.44 & . \\
\hline 24 & 6 & $I \cdot 0764$ & . & 0.29 & 13.6 \\
\hline 30 & I 2 & 1.0715 & $2 \cdot 6$ & 0.19 & . \\
\hline 42 & 24 & $\mathbf{I} \cdot 066 \mathbf{I}$ & . & O.II & 13.5 \\
\hline 54 & 36 & 1.0519 & . & $0 \cdot 11$ & . \\
\hline 66 & 48 & 0.9796 & . & . & $10 \cdot 0$ \\
\hline 78 & 60 & 0.9769 & $2 \cdot 3$ & . & . \\
\hline 90 & 72 & 0.9625 & . & . & $9 \cdot 4$ \\
\hline 102 & 84 & 0.9554 & . & . & . \\
\hline II 4 & 96 & 0.9677 & $2 \cdot I$ & . & $8 \cdot 8$ \\
\hline I 26 & 108 & 0.9784 & . & . & . \\
\hline 138 & 120 & 0.9628 & $2 \cdot I$ & . & . \\
\hline 150 & 132 & 0.9548 & . & . & . \\
\hline 162 & 150 & 0.9242 & $2 \cdot I$ & . & $4 \cdot 9$ \\
\hline
\end{tabular}

Behaviour of the total free reducing substances, free sugars and mannitol. At the beginning of autolysis the amount of water-extractable reducing substances contained in the mycelium of Aspergillus terreus stayed nearly at a minimum (Fig. I). At 36 days incubation the content of these materials were the highest observed, reaching to I $75 \mathrm{mg}$. $/ 100 \mathrm{~g}$. dry mycelium. After that time the amount of total free reducing substances sharply decreased to values fairly constant in the range $300-400 \mathrm{mg}$./ $100 \mathrm{~g}$. dry mycelium. The behaviour of free glucose showed a very similar pattern (Fig. I) to that of total free reducing substances. Glucose accounted for an average of $70 \%$ of the total reducing power observed for the aqueous extracts. From the 40 th day of incubation xylose (Fig. I) tended to decrease. No appreciable amount of xylose was detected between 66 and 78 days of incubation.

During the phase of growth (9 days) mannitol was present in mycelium of Aspergillus terreus at (Fig. 2) 6.I g./I00 g. dry mycelium. As incubation proceeded this amount decreased sharply to the 18 th day of incubation (zero days of autolysis) when $2.5 \mathrm{~g}$. 
mannitol/roo g. dry mycelium were present. At the beginning of autolysis its concentration decreased at a slower rate; between the 72 and 84 days the concentration of mannitol remained constant.

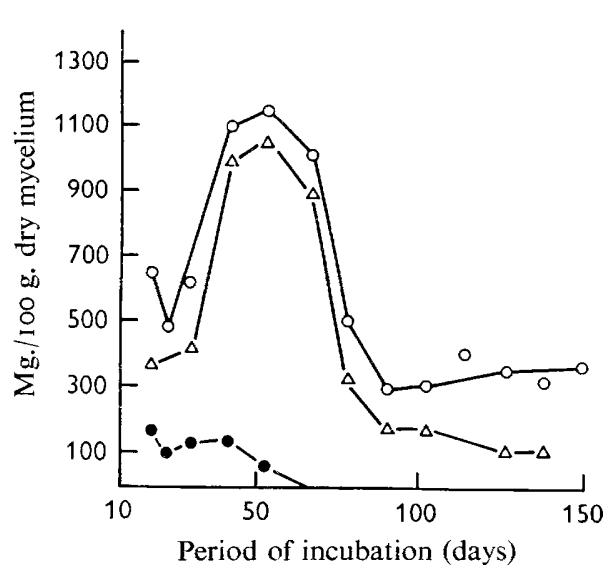

Fig. I

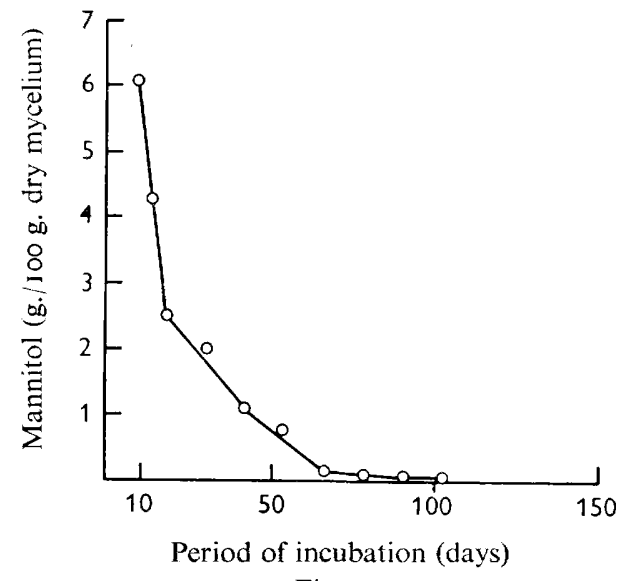

Fig. 2

Fig. I. Changes in the concentration of total free reducing substances $\bigcirc$; free glucose $\triangle$; xylose $\bullet$, in autolysing mycelium of Aspergillus terreus grown in a medium with $\mathrm{NH}_{\mathbf{4}}^{+}$ as $\mathrm{N}$ source.

Fig. 2. Content of mannitol in autolysing mycelium of Aspergillus terreus grown in an acid medium.

\section{Behaviour of the amino acids and its variation with age}

The nature and amounts of free amino acids released from mycelium harvested at different times is shown in Table 3. Thirteen different amino acids were identified; one, present in relatively small amount, was not identified (unknown). The total content of these free amino acids increased between 7 and 9 days of incubation to a maximum. Thereafter the general picture was of decreasing concentration both at the end of the log phase and during the pre-autolytic stages. Asparagine, proline, tryptophan and phenylalanine disappeared (Table 3 ) in the pre-autolytic period. Spots due to these amino acids were not seen on the chromatograms at zero day of autolysis. The maximum concentration, $(2.454 \mathrm{~g}$./ $100 \mathrm{~g}$. dry mycelium $)$ at the 9 th day, diminished by $86 \%$ during the 9 days before autolysis. From the beginning of the autolytic phase to the end of the period studied the total concentration of the free amino acids decreased again by $8 \mathrm{I} \%$, with respect to the concentration present at zero day of autolysis. Apart from serine, which was easily detectable throughout the whole cycle, no other amino acid was observed at the later stages of autolysis. Leucine, serine, threonine and alanine were the most abundant constituents in the pool; the sum of these four components formed more than $50 \%$ of the total content of amino acids present at each date.

\section{DISCUSSION}

Cessation of growth of Aspergillus terreus in these experiments seemed to take place when the carbohydrate source (glucose) had been almost completely consumed. The amount of glucose present in the culture filtrate (determined by Somogyi's method) 


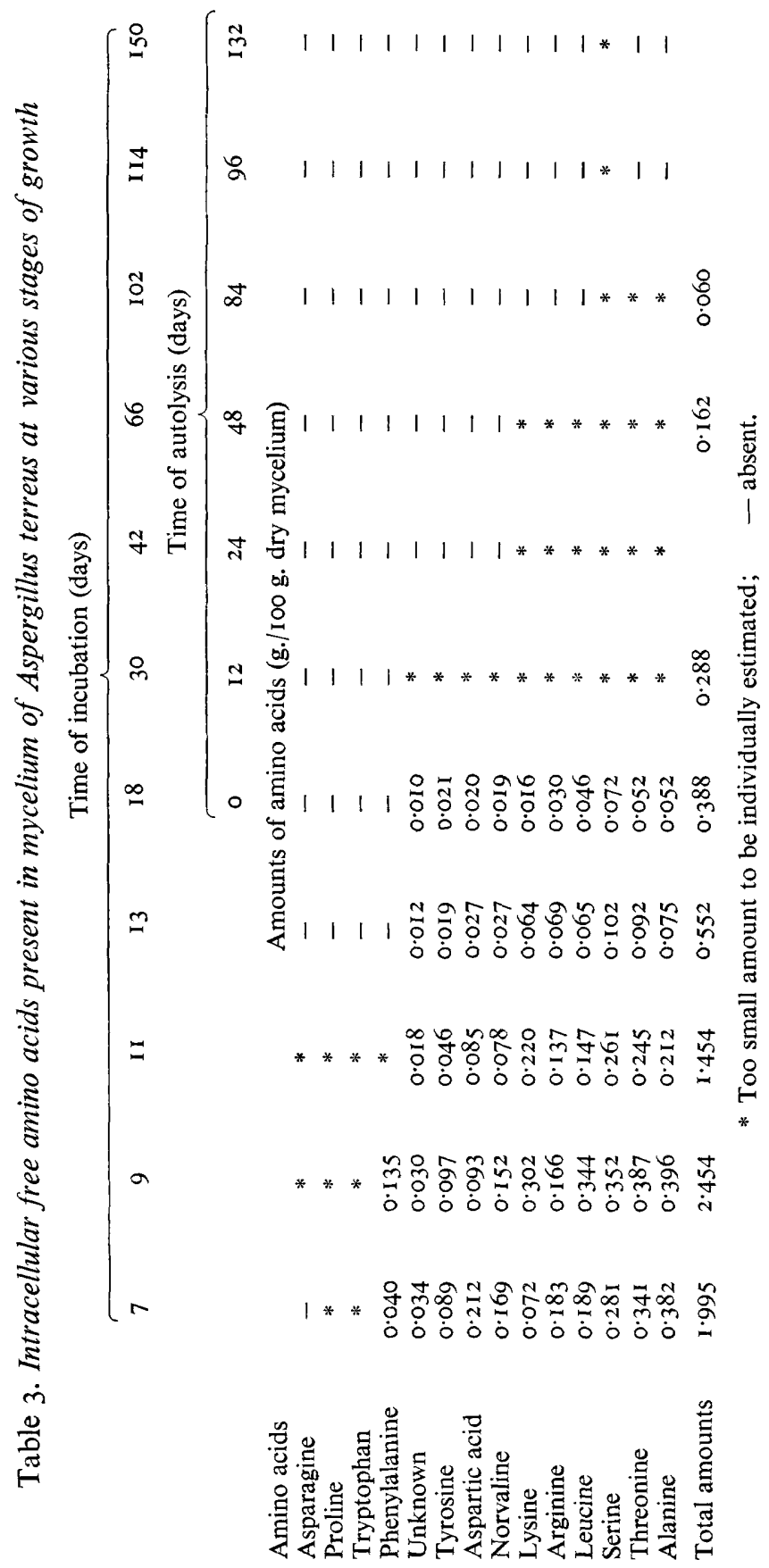


stayed practically constant (Table I) when autolysis set in. Crewther \& Lennox (1953) found similar results for $A$. oryzae grown in a medium containing $\mathrm{NH}_{4}^{+}$as $\mathrm{N}$ source.

The decrease in mycelial dry weight by Aspergillus terreus $(14.6 \%)$ in the present experiments is of the same order as that found by Ritter (1955) for A. niger (17.6\%). A nearer value (I $4.4 \%$ ) was reported by Ritter for a strain of $A$. niger which he called strain ' $\mathrm{S}$ '. The fungi in both cases were grown in an acid medium.

With respect to the behaviour of fat during autolysis it can be seen in Table 2 that a continuous decrease of mycelial lipids took place before and after the beginning of autolysis. Similar results were observed for Aspergillus terreus grown in a medium physiologically alkaline, in which there was a continuous diminution in the content of mycelial fat throughout the whole period of autolysis (Lahoz, 1967).

The increase in the concentration of free glucose in the mycelium of Aspergillus terreus, at a certain stage of autolysis, seems to be a common feature for both 'alkaline' (Lahoz, 1967) and 'acid' autolysis.

The disappearance of free amino acids from mycelium of Aspergillus terreus began at a stage in which autolysis, measured as decrease in mycelial weight, had not begun. Similarly the content of free amino acids in mycelium of $A$. flavus decreased during both the $\log$ and the autolytic phases (Pillai \& Srinivasan, 1956), whereas for Microsporum canis the maximum concentration of the pool of amino acids was observed towards the end of the $\log$ phase, with a continuous decrease thereafter (Chattaway, Toothill \& Barlow, 1962).

This research was financed in part by a grant made by the United States Department of Agriculture under P.L. 480. The work reported here formed part of a Ph.D. thesis submitted in the Faculty of Pharmacy of the University of Madrid (C. García-Tapia, 1966). One of us (C. G.-T.) is greatly indebted to the Comisaría de Protección Escolar del Ministerio de Educación y Ciencia for a generous grant.

\section{REFERENCES}

Baliga, B. R., Krishnamurthy, K., Rajagopalan, R. \& Giri, K. V. (I955). A simple method for desalting biological fluids for chromatography. J. Indian Inst. Sci. 37, I 8.

Behr, G. (1930). Uber Autolyse bei Aspergillus niger. Arch. Mikrobiol. 1, 418.

Chattaway, F. W., Toothill, C. \& Barlow, A. J. E. (I962). The amino acid metabolism of Microsporum canis. J. gen. Microbiol. 28, 27 I.

Crewther, W. G. \& Lennox, F. G. (1953). Enzymes of Aspergillus oryzae. III. The sequence of appearance and some properties of the enzymes liberated during growth. Aust. J. biol. Sci. 6, 410.

Fiske, C. H. \& SubbaRow, Y. (I925). The colorimetric determination of phosphorus. J. biol. Chem. 66, 375 .

Giri, K. V., Radhakrishnan, A. N. \& Vaidyanathan, C. S. (I953). Circular paper chromatography. Part VI. The quantitative determination of amino acids. J. Indian Inst. Sci. 35 , 145.

Kay, R. E., Harris, D. C. \& Entenman, C. (1956). Quantification of the ninhydrin color reaction as applied to paper chromatography. Arch. Biochem. Biophys. 63, I4.

LAHOZ, R. (1967). Quantitative changes in the content of non-nitrogenous compounds during autolysis of Aspergillus terreus. J. gen. Microbiol. 46, $45 \mathrm{I}$.

Lahoz, R., Reyes, F. \& Beltrá, R. (1966). Some chemical changes in the mycelium of Aspergillus flavus during autolysis. J. gen. Microbiol. 45, 41 .

Pillai, N. C. \& Srinivasan, K. S. (I956). The amino acid metabolism of Aspergillus flavus. J. gen. Microbiol. I4, 248.

Ritter, R. (I955). Physiologische Untersuchungen an Zygomyceten. Arch. Mikrobiol. 22, 248.

SCHMIDT, M. (1936). Makrochemische Untersuchungen über das Vorkommen von Chitin bei Mikroorganismen. Arch. Mikrobiol. 7, 24I. 